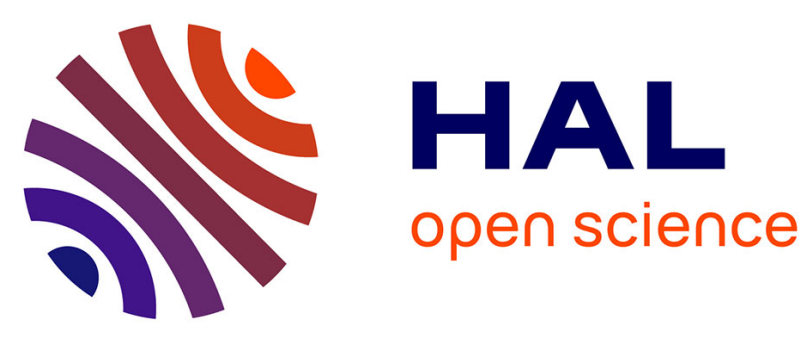

\title{
Juridiction administrative
}

Michel Gautret

\section{To cite this version:}

Michel Gautret. Juridiction administrative. Revue forestière française, 1968, 10, pp.685-686. 10.4267/2042/20212 . hal-03385838

\section{HAL Id: hal-03385838 \\ https://hal.science/hal-03385838}

Submitted on 19 Oct 2021

HAL is a multi-disciplinary open access archive for the deposit and dissemination of scientific research documents, whether they are published or not. The documents may come from teaching and research institutions in France or abroad, or from public or private research centers.
L'archive ouverte pluridisciplinaire HAL, est destinée au dépôt et à la diffusion de documents scientifiques de niveau recherche, publiés ou non, émanant des établissements d'enseignement et de recherche français ou étrangers, des laboratoires publics ou privés. 


\section{III. - JURIDICTION ADMINISTRATIVE}

A) - Aflaire époux DOMMÉ - Groupements forestiers. Validité d'une décision du ministre de l'agriculture ayant approuvé les statuts d'un groupement forestier et légalité du décret $n^{\circ}$ 54-1302 du 30 décembre 1954. Jugement du tribunal administratif de Nantes du 15 janvier 1965 et arrêt du conseil d'Etat du 20 octobre 1967 (instance $n^{\circ} 66$ 178). (Rec. Lebon, page 382).

Les époux DOMMÉE avaient engagè une procédure devant les juridictions administratives, en vue de faire annuler une décision par laquelle le ministre de l"agriculture avait approuvé un projet de statuts de groupement forestier. Le conseil d'Etat eut d'abord à se prononcer en règlement de juges. Il estima que la réglementation relative aux groupements forestiers concernait des questions agricoles et que la décision ministérielle attaquée était une mesure individuelle relative à des forêts déterminèes; la haute assemblée administrative reconnut par suite, en la matiére, la compétence du tribunal administratif dans le ressort duquel se trouvaient les forêts en question et s'opposa à la compétence du tribunal administratif de Paris.

Le tribunal administratif de Nantes, saisi ensuite du litige, constata la légalité des décrets relatifs aux groupements forestiers; il fut également jugé que l'approbation des statuts attaqués entrait dans le champ d'application du décret du 30 décembre 1954 et que si certains étangs avaient été incorporés dans le périmétre du groupement c'est parce que l'administration avait déclaré que c'était des dépendances de la forêt et qu'une telle appréciation ne pouvait être mise en cause par la juridiction administrative. Le tribunal administratit constata également que les groupements forestiers constituaient des sociétés civiles dont les statuts ne pouvaient étre contestés que devant les tribunaux judiciaires. Les adversaires furent déboutès, mais firent appel.

Le conseil d'Etat se prononça définitivement le 20 octobre 1967.

La haute assemblée administrative confirma la décision de première instance et déclara :

1") que le décret du 30 décembre 1954 était légal, ayant été pris conformément à la loi du 14 août 1954 ; les dérogations aux articles 826 et 827 du code civil sur le partage en nature et la licitation des biens, qui avaient été établies, faisait bien partie des modifications autorisées ;

$\left.2^{\circ}\right)$ que le fait que la création d'un groupement forestier profite à des intérêts privés ne saurait entacher d'illégalité l'approbation des statuts par le ministre de l'agriculture et qu'il n'y avait aucun empêchement à ce que le groupement forestier réunisse toutes les terres d'une même indivision, du moment que c'était dans l'in térêt de la gestion :

$\left.3^{\circ}\right)$ qu'il était normal que soient englobées dans le groupement forestier des dépendances de nature à faciliter la mise en valeur générale, comme des étangs.

L'arrêt du conseil d'Etat du 20 octobre 1967 présente un grand intérêt de principe en ce qu'il consacre la légalité du décret du 30 décembre 1954, pris pour l'application de la loi du 14 août 1954 et en ce qu'il admet une large interprétation de la notion de dépendances non forestières incorporables à un groupement forestier.

B) - Affalre PASQUET. Responsabilité de la puissance publique en raison des restrictions apportées par un arrêté préfectoral à l'exerclce du droit de destruction des nuisibles. Jugement du tribunal administratif de Dijon du 28 novembre 1966. Arrêt du conseil d'Etat du 12 juin 1968 (instance $n^{\circ} 72012$ ).

Le sieur PASQUET avait déposé, à la sous-préfecture, une demande de destruction d'animaux nuisibles (pigeons) au fusil avec des chiens et des aides pendant la période de fermeture. Cette demande fut acceptée, mais d'importantes restrictions furent apportées aux destructions que demandait $M$. PASQUET.

II y eut de graves dégâts causés aux futures récoltes par les pigeons. Aussi un recours fut-il intenté : $1^{\circ}$ ) en vue de faire annuler l'arrêté du sous-préfet portant autorisation de destruction de nuisibles $; 2^{\circ}$ ) en vue d'obtenir une indemnité pour le préjudice subi en raison des restrictions excessives apportées aux conditions de destruction. 
Le tribunal administratif de Dijon fit remarquer que le recours en annulation de l'arrêté préfectoral n'était pas recevable, comme intenté plus de deux mois après la notification de l'arrêté. La juridiction administrative constata qu'il n'y avait pas forclusion en ce qui concerne la demande d'indemnité relative à une question de plein contentieux, mais le tribunal estima que le sous-préfet était en droit d'apprécier l'opportunité de la demande de destruction de nulsibles, compte tenu des conditions locales et qu'en l'espèce, les restrictions fixées ne constituaient pas les éléments d'une faute de nature à engager la responsabilitè de l'Etat.

Sur appel du sieur PASQUET, le conseil d'Etat déclara que * s'agissant uniquement en l'espèce d'oiseaux nuisibles, le requérant n'est pas fondé à soutenir que l'autorisation qui lul était accordée devait être valable en tout temps et sans conditions ". De plus, il fut précisé qu'en l'espèce, la décision du sous-préfet n'était pas fondée sur des raisons inexactes et que donc il ne pouvait y avoir faute de nature à engendrer une responsabilité administrative.

C) - Affaire Assoclation de pêche et de pisclculture du Gave de Pau. Conflit entre deux associations de pêcheurs prétendant bénéflcier toutes deux d'un droit de préférence au sujet de l'attribution de droits de péche sur un cours d'eau du domaine public visé à l'article 403 du code rural. Jugement du tribunal administratif de Pau du 3 avril 1968. Instance $\mathrm{n}^{\circ} 2480$.

Deux associations de pêcheurs prétendaient toutes deux bénéficier du droit de préférence prévu par l'article 5 du décret du 25 octobre 1957 pour se voir attribuer un lot de pêche fluviale, soit à l'amiable, soit à la suite d'une adjudication restreinte.

Pour éviter tout conflit, l'administration gestionnaire du cours d'eau domanial décida d'user du procédé de l'adjudication publique. L'association de pêche et de pisciculture du Gave de Pau forma un recours en vue de faire annuler la décision administrative, cette association prétendait que l'administration était tenue par les dispositions de l'article 5 précité et ne pouvait user que de l'adjudication restreinte.

Par décision en date du 3 avril 1968, le tribuna! administratif de Pau la débouta ef proclama qu'en vertu des articles 1 et 2 du décret du 25 octobre 1957 l'administration détenait * le pouvoir discrétionnaire de décider si tel lot de pêche déterminé serait affermé à l'amiable aux sociétés de pêche dans les conditions visèes à l'article 3 et suivants ou s'il serait adjugé aux enchères publiques ".

Miche! GAUTRET

Charge de mission contractue Mission de coordination législative et reglementaure

Direction des forêts

iter. Avenue de Lowendal PARIS - (7e)

\section{A VEN D R E}

REVUE FORESTIÈRE FRANÇAISE : années 1949 à 1966 (à l'exception de février et juillet 1966)

S'adresser à Monsieur M. HAGEN, 15, Rue des Vergers - 68 - WESTHALTEN 